\title{
ICT Driven Knowledge Management in Developing Countries: A Case Study in a Chinese Organisation
}

\author{
Jin Tong and Siraj A. Shaikh \\ Department of Computing and the Digital Environment, \\ Faculty of Engineering and Computing, Coventry University, Coventry, CV1 5FB, \\ United Kingdom \\ jintongcn@gmail.com, s.shaikh@coventry.ac.uk
}

\begin{abstract}
Current research of knowledge management (KM) is mostly based on experience in developed countries that are already becoming knowledge economies [16]. In general, ICT (information and communication technologies) is playing an important part of $\mathrm{KM}$ in these countries. Applications of their $\mathrm{KM}$ models and frameworks might not yield expected results in developing countries. It is necessary to help organisations in developing countries to understand the issues of KM in their local context. Towards this goal, this paper explores current KM practice in China through a case study of a recently created Chinese mobile phone company (referred to as Lotus). The researchers present a model demonstrating how ICT can promote effective KM based on the Lotus case findings. However, this model is more applicable in the wider developing countries context than just China.
\end{abstract}

Keywords: Knowledge Management, ICT adoption, Chinese organizations.

\section{Introduction}

Increasingly organisations are keen to adopt knowledge management (KM) strategies to achieve organizational objectives, including competitive advantages, shared intelligence, improved business performance and higher levels of innovation. This trend started in developed countries (such as Japan, US and EU) decades ago. KM applications within these countries have reached a mature level. KM implementations within developing countries, however, are still at an early stage. In the case of China, for example, $\mathrm{KM}$ is a relatively new concept and its importance has not yet been fully explored [2].

The role of information and communication technologies (ICT) as technical support for KM is widely acknowledged and emphasised in current literature. ICT tools, for example, have been proposed to develop knowledge databases or to support effective communications for knowledge sharing purposes. Current work on the application of ICT to promote effective KM mostly aims to help organisations in developed countries. There is not much work on effective KM for organizations in developing countries, such as China, especially how ICT acts as a facility to promote positive social change in supporting KM. 
To address this gap, this paper reports on a case study conducted in a Chinese organisation called Lotus. Lotus is a recently created mobile phone manufacturing company. Established by a group of 15 active professionals from the mobile phone industry, who decided to come together in 2005 to form Lotus, it designs and manufactures tailor-made mobile phones and other wireless terminal products for markets in China, South America and Europe. Their clients are brand manufactures, mobile phone distributors and small-medium sized wireless product operators. Lotus is representative of a typical small organisation in China and KM practices observed in the organisation reflect on the wider sector in the country. It has also been studied in authors' another paper [1], which explored cultural influences on KM in Chinese organisations. This paper, in contrast to the previous one, aims to focus on the role of ICT as the driver underlying KM and attempts to analyse it from a non-cultural perspective.

The rest of this paper is organised as follows. Section 2 reviews background and literature relevant to the ideas presented in this paper. Section 3 describes the research methodology used to study the Lotus case. Section 4 conducts an analysis of the findings of this case study. Section 5 presents a model explaining the role of ICT in KM specifically in the context of developing countries. Section 6 finally concludes the paper with observations and remarks.

\section{Background}

This section sets the context and discusses why ICT is important for developing countries, such as China, and how it has been applied for effective KM up until now. Given Lotus as a choice of case study, Section 2.3 pays particular attention to China in this regard.

\subsection{The Importance of ICT for Developing Countries}

There is ample evidence from developed world to acknowledge that ICT is a major driving force for economic development. The invention of the Internet and its widespread applications are even held by some [3], [4] as the twilight of the third industrial revolution, comparable to the role played by the internal combustion engine and the railroad in the second industrial revolution. Hoffman [5] believes that effective ICT adoption will help organisations to substantially enhance their international competitiveness. ICT has become a "critical infrastructure for competing in an information-intensive global economy" [6, p. xi]. Meanwhile, some studies [7], [8], [9] have developed the argument that ICT investments are necessary to stimulate economic development and as a means of enhancing national productivity and competitiveness. This has been called the "information technology-led development" strategy [9]. It is recognised that ICT applications can enable improvements in productivity and quality in a number of sectors relevant to developing countries, such as agriculture, manufacturing, infrastructure, public administration, and services such as finance, trade, distribution, marketing, education, and health [10]. The following statement from a World Bank discussion paper strongly supports this: 
"Information technology dramatically increases the amount and timeliness of information available to economics agents - and the productivity of processes to organize, process, communicate, store, and retrieve information... [and this] has major implications for developing countries, as producers and users of this technology." [6, p. 1]

\subsection{ICT Applications in KM}

$\mathrm{KM}$ is one of the emerging trends for organisations to sustain competitive advantages. Many firms that embrace KM as a key organisational policy eventually go on to become industry leaders [11]. Their success shows the benefits of effective KM to an organisation. KM is about directing people's view on knowledge, guiding people's behaviors of sharing their knowledge, designing right strategies and using effective approaches to promote knowledge creation, dissemination and leveraging to fulfill organisational objectives.

Nonaka and Takeuchi [12] developed a knowledge creation model that obtained widespread acceptance within the KM community. It identifies four different processes through which knowledge is created - socialization, externalization, combination and internalization. This SECI model has convinced many practitioners that organisational $\mathrm{KM}$ practice can be effectively improved if the knowledge is managed in an explicit / codified format. Since then, many researchers have attempted to apply ICT technologies to maximally capture, codify and store knowledge within organisations [13]. Organisations in the developed world have made considerable progress in implementing effective KM. However, many developing countries, such as China, started this progress relatively much later. With rapid economic development over the past 25 years, most Chinese organisations are at a stage that massive fundamental knowledge - knowledge that can be easily captured, codified and stored - has not been effectively managed. Analysis in subsequent sessions of this paper serve to highlight that such a situation still exists in the case of Lotus for example.

\subsection{Current ICT Adoption in China}

Learning from developed countries' experience, Chinese government has made significant investments in ICT and has come to view it as an important contributor to industrialization and economic development [17]. While reviewing China's ICT adoption and diffusion, Meng and Li [4] insist that compared to relatively high IT expenditures on hardware $(88.1 \%)$, the consumption of software and IT service in China is very low (7.3\%). It indicates that there is lack of ICT usage in Chinese organisation. They also believe that "it is reasonable to assume that as computer usage reaches a point of saturation within the next several years, the percentage of software and IT services will go up significantly" [4, p. 281]. However, there is little literature available on how ICT is adopted in China for management purposes in organisations.

\section{Research Methodology}

This paper attempts to investigate the current KM practice within Lotus, and explores some of the reasons underlying such a state of practice. A qualitative research 
methodology was adopted in this study. To ensure that adequate care was taken in structuring and analyzing the case, the following four steps were taken.

1. A learning day was organised as part of an organisational day trip. Within a relaxed environment, the authors established initial communications with all employees and helped them to have a common understanding of knowledge management, and the purpose of the present case study.

2. Observation at the work place was organised, lasting three days, to achieve an overview of knowledge flows within Lotus, and identify the key interviewees for in-depth interviews. Through participant observation at the work place, the authors managed to get familiar with the potential interviewees' working language.

3. In-depth interviews with the management team and selected employees was organised, which included interviews with 18 Lotus staff members, including the Chief Manager, R\&D director, Human Resources manager, 5 R\&D design team leaders, and 10 selected general employees. Each interview lasted approximately 1.5 hour. The interview contents have been taperecorded and subsequently transcribed.

4. In order to ascertain the validity of findings, meetings with volunteered Lotus participants were held regularly. Meanwhile, consultations with the management team on findings created opportunities to introduce necessary $\mathrm{KM}$ solutions to business processes. The study process also resulted in consensus and commitment of research participants on formal KM approaches (e.g. applications of knowledge maps, [14]).

\section{Field Results and Analysis}

Traditional Chinese cultural values pervasively influencing the management mode and organisation is one of the outstanding characteristics of Chinese organisations [15]. From a cultural perspective Lotus has been studied earlier [1]. The study explored the practice of keeping knowledge implicit in Chinese enterprises. The study revealed that employees like to keep their knowledge implicit and are willing to informally share their knowledge. A series of factors derived from the Chinese culture including

- hierarchy consciousness,

- fear of losing face,

- a sense of modesty,

- competitiveness, and

- a preference for face-to-face communication

Can act as barriers to knowledge initiatives within Chinese organisations. Trust in intra personal relationships among employees can partly mitigate the impact of above cultural characteristics. However, at a macro organisational level there is still a need to share knowledge using explicit and formal KM approaches.

Apart from the above cultural factors, some other management related issues, such as working procedures and business strategies, also affect the current KM practice within Lotus. Focusing on these issues, this section attempts to explore the KM gap and identify the major reasons contributing to this gap in Lotus. 


\subsection{KM Gap within Lotus}

Prior to starting the field work, the authors had expected to find KM practices in Lotus relatively more effective compared to other Chinese organisations. There are several reasons to allow such an expectation. First, ICT hardware investment in Lotus is at a high level. PC and internet coverage inside the company is $100 \%$. Such conditions make Lotus very similar to technology-based organisations in developed countries. Secondly, 3 out of 5 senior managers in the Lotus management team have a background of working in leading telecommunication companies in developed countries. Because of their rich international working experience, it was also expected that KM concepts should be familiar to them. Finally, given that Lotus is a company in the ICT industry, employees' willingness to adopt ICT related KM approaches into daily work is expected to be higher than other Chinese companies. Current KM practices within Lotus were found to be on the contrary however. This KM gap is reflected as follows:

Management team members' perceptions towards KM are not encouraging. KM is still a new concept to Lotus staff. Apart from the chief manager, the rest of senior managers are not familiar with the concept of KM. General Lotus staff do not have sufficient awareness of the importance and needs of applying KM strategies.

There are no formal KM strategies and approaches within Lotus. Codified and explicit knowledge is comparatively rare in this organisation. Like other Chinese organisations, the majority of workforce in Lotus is the staff in the manufacturing department, which routinely creates several product lines. However, the nature of business determined that $\mathrm{R} \& \mathrm{D}$ department plays a decisive role for the company, in order to survive within keen competition with other similar organisations, Lotus needs to possess an experienced R\&D team capable of leveraging competitive advantages. There are approximately 50 design engineers in R\&D department. During the daily work process, their own knowledge gaps forced them to obtain new knowledge from other resources. However, knowledge sharing within this department primarily depends on informal approaches, such as social events (e.g. staff have dinner together), seeking personal assistance from others, etc. Therefore, massive fundamental knowledge has not been captured, codified or stored formally.

Knowledge flows are not flexible enough - only top to bottom through the organisational hierarchy. In most successful organisations that have supportive KM environment, knowledge can be transferred / shared through various paths. Knowledge flows in those organisations can be very complex and flexible. However, current KM practice in Lotus shows that knowledge flows only from top to bottom level through the organisational hierarchy.

\subsection{Reasons Contributing to the Gap}

Further investigation reveals several reasons underlying the KM gap that exists at Lotus.

Reason 1 - Insufficient ICT adoption in Lotus. The IT support team has set up a website for all employees, which facilitated an online forum, document storage, and 
messages from the company's leadership. In general, IT support staff attempted to design the organisational website as a formal knowledge sharing facility. But the use of the site is not encouraging. Embedded functions in this website are rarely used. When the authors interviewed anticipated users of this website, most of them even did not know the existence of such functions.

This incident reveals the issue of insufficient ICT adoption in Lotus. Unlike most successful organisations in developed countries, the potential of ICT is not fully exploited within Lotus. Most staff members use the organisation's intranet to send email, chat online with colleagues, or use web search engines to get information. R\&D engineers work on PCs everyday to design products by using relevant software. However, administration staff use their computers to do the very basic paper work. For instance, instead of creating a HR database, HR department is still using paperbased folders to maintain employee records. There are no standard written working procedures within any department, though most employees are familiar with their work process because of their work experience in the field. R\&D engineers do not maintain problem solving records or any database to manage their design work processes. The traditional training method - of one master supervising one apprentice is still being used in Lotus. When a new employee is hired, a mentor (a senior staff member) is assigned by the HR department to assist the new member with any problem he/she may have during the work process. These examples evidently indicate that in Lotus, ICT has been only used as a supplement for daily manual work, but not as an essential work force at the general management level.

While organisations in developed countries are trying to avoid excessively depending on ICT to manage their intellectual capital, Lotus does not truly recognize the vital function of ICT in its KM. Due to low effective usage of ICT, massive explicit knowledge has been kept implicit within Lotus, although such knowledge is normally explicitly managed (codified) through ICT in organisations in developed countries.

Reason 2 - Strict hierarchy within Lotus. There is a clearly defined organisational hierarchy in Lotus. Within this organisational structure chart, each employee can be located into specific position according to their responsibilities. Meanwhile, there is another informal hierarchy inside this organization (Figure 1). In this informal hierarchy, company managers are still at the top level. Elderly staff and employees who joined Lotus are at higher levels then those just joined this company. New graduates (recently employed Lotus staff) who do not have any experience in related working field are at the bottom level.

Employees' traditional hierarchy consciousness results in this informal organisational hierarchy. Due to the fear of breaking rules and policies, formal organisational hierarchy always held predominant importance. So even in this informal hierarchy, people who are at managing positions are still at the top level. The tradition of respecting elders and sense of modesty made new graduates volunteered to stay at the bottom level in this hierarchy. In addition, not just age, but also experience and time of working in the organisations can be the reasons for an employee to be respected and rank at a higher level, even though he or she may be biologically younger than others sometimes. 


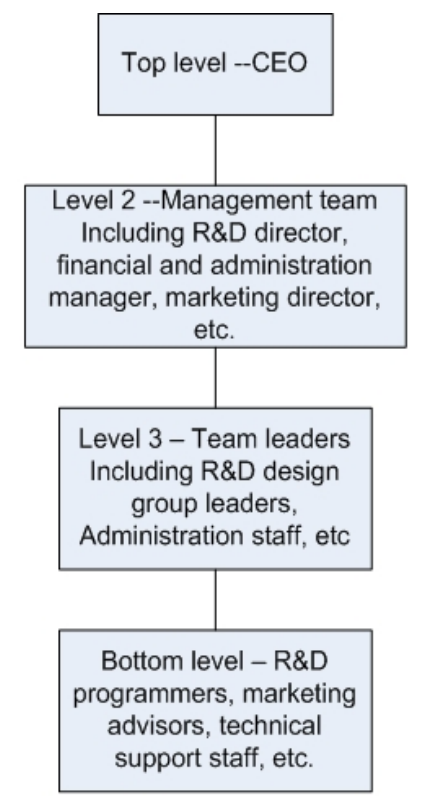

Formal organisational hierarch in Lotus

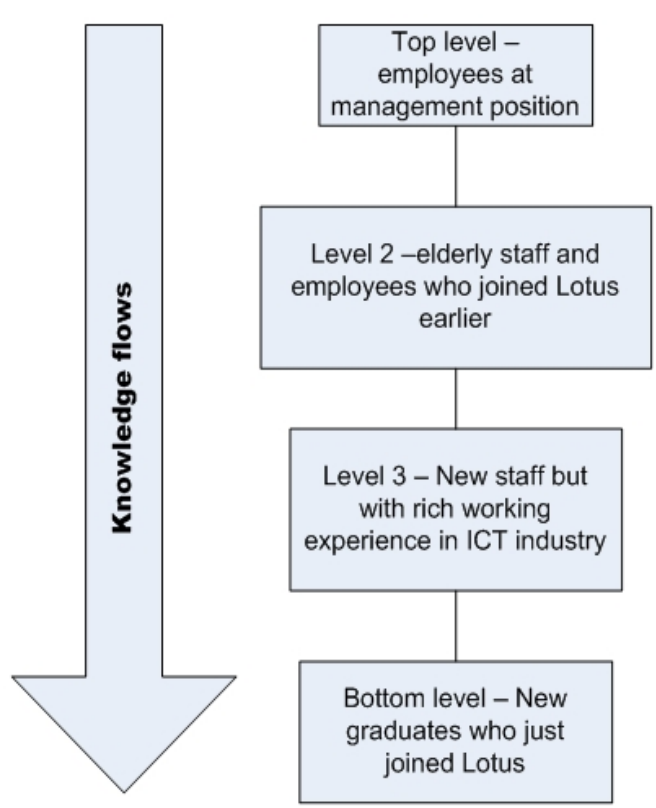

Informal organisational hierarch in Lotus due to employees' traditional hierarchy consciousness

Fig. 1. Strict organisational hierarchy (formal and informal) in Lotus

In both formal and informal hierarchy in Lotus, junior employees (staff at lower level, such as lower-position, younger, newer staff) are expected to follow seniors' advice. Seniors are supposed to teach or pass on their knowledge and experience to juniors in organisations. Following seniors' suggestions is the right way to show juniors' respect to them. Lotus's new staff mentoring policy (one master supervising one apprentice) is one example showing that knowledge flows from top to bottom in this company. So obviously, managers and senior staff rarely receive knowledge from their subordinates and juniors. This situation causes an 'unequal' knowledge sharing environment.

Reason 3 - Lack of supportive policies and practitioners. Investigation shows that there are no qualified KM personnel within Lotus. KM in China only started in 1990s. Only a few Chinese universities set KM courses and foster KM professionals. There are very few qualified KM professionals available compared to the size of Chinese KM market. Organisations with mature knowledge management facilities in developed countries, senior managers and HR administrative personnel are normally the KM principals. However, such administrative staff at Lotus do not have required $\mathrm{KM}$ skills and knowledge to be responsible for KM related tasks.

Hoarding knowledge is a natural tendency. Knowledge sharing hence must be encouraged and rewarded. The organisational website mentioned earlier provides a convenient platform to staff to share ideas and exchange knowledge. But hardly anyone visited this website. Obviously, Lotus staff did not take this seriously, because 
they are not encouraged to use it. Without senior managers' support and encouragement, KM activities always do not have high execution priority. As a result, when activities of knowledge sharing conflict with other action plan, the organisation's policies specify that other action plans go first. For example in Lotus, R\&D department is always developing several products for different clients at the same time. All R\&D engineers are allocated to different project groups. So employees from the same team are working on different projects. Meanwhile, the organisation has a bonus policy, which allows employees get more bonuses if their project team develops better product. Such bonus policy obviously can increase the employees' commitment on their project. But at the same time, it also creates a harmful atmosphere, in which employees would not like to share knowledge with the project competitors.

In summary, lack of supportive KM policies and qualified practitioners causes a non-supportive organisational environment for effective KM in Lotus.

\section{Discussion}

By explaining why it is necessary to improve the current KM practice within Lotus, the value of effective KM to Chinese organisations is highlighted in this section. A more widespread adoption of ICT is proposed to bridge the Lotus gap. The role of ICT as an essential enabler for KM within Chinese organisations is illustrated in a model. This model also shows applicability in the wider developing countries context than just China.

\subsection{The Need to Improve Current KM Practice}

China has put high-priority efforts in becoming a more knowledge-based economy and society, and this means KM is very important [18]. Being caught in the global economic downturn, increasingly Chinese organisations have to prepare for more severe marketing competitions. Since effective KM could help organisations sustain their competitive advantages (e.g. higher production and economic efficiencies), improving Chinese organisations' KM practices is necessary. The Lotus case sets a good example to demonstrate such a need.

With the expansion of mobile phone market, more and more products have to be designed at the same time. Without a standard R\&D design procedure, a Lotus employee may waste time in redoing the same job (e.g. some reusable driver programs have been written repeatedly in Lotus). Therefore, explicating such implicit knowledge is required to improve employees' work efficiency and minimize the production duration. Furthermore, without a written record of solved problems during the work processes, mistakes can be repeated and solution seeking time can be longer than expected. It is also necessary to produce standard staff training material to effectively pass on necessary knowledge as well as reduce new staff training time. Any formatted documents can also become written evidence for future analysis of one project's success or failure.

According to Lotus's recruitment plan, more inexperienced staff (e.g. new graduates and people who have never worked in this field) will be employed in order 
to increase saving on the HR budget. It will be very difficult for these potential employees to start delivering high quality work without any valuable codified knowledge available in Lotus. In this case, managing knowledge using ICT is a logical starting point to facilitate knowledge sharing.

\subsection{The Use of ICT to Bridge the KM Gap}

$\mathrm{KM}$ in developed countries has provided ample evidence to indicate that one main role of ICT in KM is to accelerate the speed of knowledge capture, transfer and storage. This role emphasized the importance of ICT in the dimension of technical supporting. KM progress always comes with positive organisational changes. Effective KM strategies in an organisation should be able to increase employees' motivation of sharing their knowledge, and to help employees to overcome their psychological barriers in seeking / receiving knowledge from others. Therefore in the dimension of promoting organisational change, will ICT still play an important role? Analysis shows that it will. Figure 2 below clearly explain how ICT application can promote such positive organisation changes.

Once organisations set up KM friendly policies and employ qualified KM practitioners, ICT adoption as a basic KM approach can be encouraged. Good organisational policies should also foster a flatter organisation structure. Employees can take different roles in different projects in organisations, so their position in the formal organisational hierarchy can be more adaptive. As the formal hierarchy became flexible, knowledge flows that pass through this structure can be more dynamic.

However, improvement to the informal organisational hierarchy needs the positive impact of widespread adoption of ICT. Once an organisation starts to use ICT to maximally codify fundamental knowledge, explicit knowledge within this organisation will be available in different format, such as website, shared documents, and so on. Employees will not need to seek for required knowledge in person all the time. This can be extremely helpful for employees that are at the higher level in the organisational hierarchy to receive knowledge from the ones at lower level. Their psychological barrier of feeling embarrassed when receiving knowledge from subordinates and youngsters can be overcome in this situation. Similarly, widespread ICT adoption can also increase employees' motivation of sharing their knowledge, especially the ones at the lower level in the hierarchy. For example, while Lotus is training one of the new staff members using their 'one master supervising one apprentice' mentoring policy, the apprentice normally would not like to show their expertise and knowledge in front of their masters. However, transferring their knowledge in another format (e.g. documents, webpage) is less possible to make them feel that they are offending the seniors in the company. Their motivation of sharing knowledge hence increases.

Although this model is generalized based on the Lotus case study, its value does not restrict in China only. The role of ICT as an essential driver of effective KM can also be applied to the wider developing countries context. According to this model (see Figure 2), ICT can enable effective KM in two dimensions. First, widespread ICT adoption can technically support managing massive fundamental knowledge, 


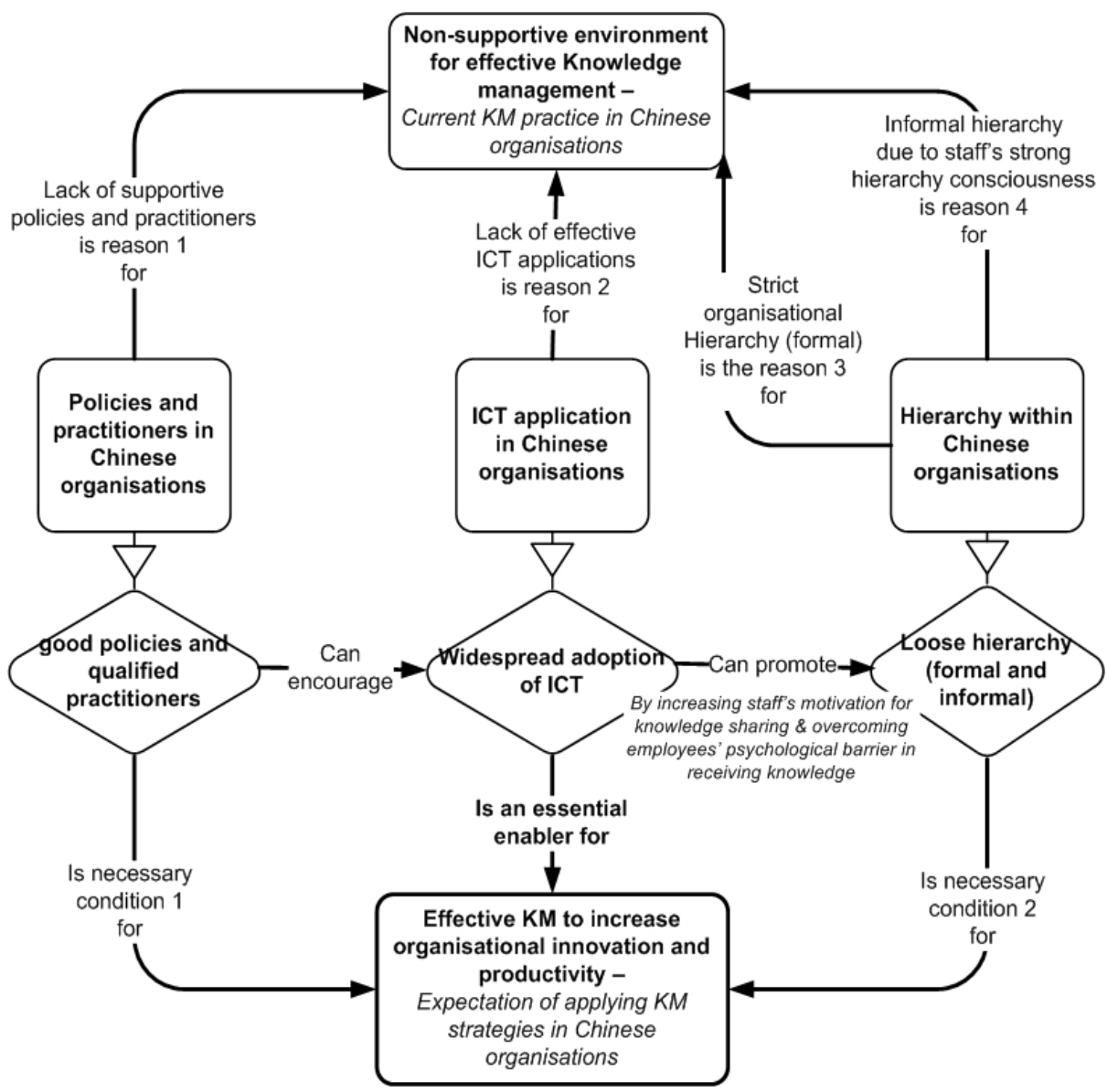

Fig. 2. Extended role of ICT in bridging the KM gap in Chinese organisations

which is the urgent problem in most developing countries [16], [18], [19]. Second, it can also promote a comparatively loose organisation hierarchy by increasing employees' motivation of sharing knowledge and overcoming their psychological barriers in receiving knowledge.

\section{Conclusion}

Through a case study in a Chinese company, this paper explores current organisational KM practice in China. The study revealed a gap between expectations of applying KM strategies and current experience in Chinese organisations. This gap caused Lotus to fail to reach expected business performance levels. Insufficient ICT adoption, strict organisational hierarchy (both formal and informal), and lack of supportive policies and practitioners can be seen as the three major reasons contributing to this gap within Lotus. Widespread ICT adoption within Chinese 
organisations is proposed to bridge gaps in knowledge sharing expectations. The essential role of ICT in effective KM is emphasized in a model (see Section 5.2) that can benefit organisations in both China and other developing countries.

This effort aims to provide an insight into KM practices in the developing world. While Lotus serves to be one example from China, it is hoped that such an exanimation is extended to other developing countries to reaffirm general conclusions drawn from this work. The crucial role that ICT plays for effective KM is acknowledged and should serve as a reminder for knowledge managers in China and the developing world at large. Further work aims to focus on a selection of specific ICT tools and technologies in their role to support KM, and the organisational changes necessary for adoption of effective KM processes.

\section{References}

1. Tong, J., Mitra, A.: Chinese cultural influences on knowledge management practices: a case study in a Chinese manufacturing enterprise. In: Proceedings of the 3rd AsiaPacific International Conference on Knowledge Management, KMAP 2006, Hong Kong (2006)

2. Peng, J., Li-Hua, R., Moffett, S.: Trend of knowledge management in China: challenges and opportunities. Journal of Technology Management in China 2(3), 198-211 (2007)

3. Kraemer, K., Dedrick, J.: Information technology and productivity: results and policy implications of cross-country studies. In: Pohjola, M. (ed.) Information Technology, Productivity, and Economic Growth, pp. 257-279. Oxford University Press, Oxford (2001)

4. Meng, Q., Li, M.: New Economy and ICT development in China. Information Economics and Policy 14(2), 275-295 (2002)

5. Hoffman, K.: Microelectronics, international competition and development strategies: the unavoidable issues - editor's introduction. World Development 13(3), 263-272 (1985)

6. Hanna, N.: Exploiting information technology for development: a case study of. World Bank Discussion Paper 264. World Bank, Washington (1994)

7. OECD: OECD Information Technology Outlook 1999. OECD, Paris (2000)

8. Asian Productivity Organisation: Information technology-led development. APO, Tokyo (1990)

9. Mody, A., Dahlman, C.: Performance and potential of information technology: an international perspective. World Development 20(12), 1703-1719 (1992)

10. Sein, M.K., Harindranath, G.: Conceptualizing the ICT artifact: toward understanding the role of ICT in national development. The Information Society 20, 15-24 (2004)

11. Davenport, T.H., Prusak, L.: Working Knowledge: How Organizations Manage What They Know. Harvard Business School Press, Boston (1998)

12. Nonaka, I., Takeuchi, H.: The Knowledge-Creating Company: How Japanese Companies Create the Dynamics of Innovation. Oxford University Press, Oxford (1995)

13. Sparrow, H.: Knowledge in Organisations. Sage, Thousand Oakes (1998)

14. Tong, J., Mitra, A.: Knowledge maps and organizations: an overview and interpretation. International Journal of Business Information Systems 3(6), 587-608 (2009)

15. Pun, K.F., Chin, K.S., Lau, H.: A review of the Chinese cultural influences on Chinese enterprise management. International Journal of Management Reviews 2(4), 325-338 (2000) 
16. Okunoye, A.: Towards a framework for sustainable knowledge management in organisations in developing countries. In: Brunnstein, K., Berleur, J. (eds.) Human Choice and Computers: Issues of Choice and quality of life in developing countries, pp. 225-237. Springer, Heidelberg (2002)

17. Press, L., Foster, w., Wolcott, P., Mchnery, W.: The Internet in India and China. Information Technologies and Internet Development 1(1), 41-60 (2003)

18. Burrows, G.R., Drummond, D.L., Martinsons, M.G.: Knowledge Management in China. Communications of the ACM 48(40), 73-76 (2005)

19. Singh, S.K.: Knowledge management practices and organisational learning in Indian Software Company. Int. J. Business Innovation and Research 3(4), 363-381 (2009) 